\title{
INFLUENCE OF CULTURE MEDIUM ON MULTIPLICATION OF LACTIC BACTERIA ISOLATED FROM ORGANIC MILK IN ORDER TO OBTAIN BIOMASS
}

\author{
Letiția, OPREAN \\ „Lucian Blaga” University of Sibiu, Romania, e-mail: letitia.oprean@ulbsibiu.ro
}

\begin{abstract}
This paper aims to establish direct and predictive methods (statistical) the possibility of obtaining lactic bacteria Lactobacillus delbrueckii var. bulgaricus in higher amounts by using culture medium enriched with carbohydrates in different percentages, for using these in obtaining organic products. The results led to the selection of MRS culture medium enriched with 1\% glucose, $2 \%$ lactose and 3\% maltose as a substrate in order to use multiplication of lactic bacteria isolated from organic milk, collected from organic farms in the area of Sibiu, Romania.
\end{abstract}

KEYWORDS: Lactobacillus delbrueckii var. bulgaricus, organic milk, enriched medium, carbohydrates, statistical analysis

\section{INTRODUCTION}

Organic products have a large and ever-growing search with the consumer market, in such a way that it is necessary and a reassessment of scientific data which converge to obtain them. Organic milk requires a number of traits which should be to define, but at the same time it is necessary and processing it with a view to obtaining of by-products to meet the requirements imposed by the European legislation in the field (Tita et al., 2012; Iancu et al., 2011). In Romania more and more farms focuses on livestock farming in ecological system and the milk result is processed in order to obtain the traditional yoghurt and cheese (Tita, 2002). For this purpose it is required the use of own lactic cultures, isolated from organic milk, with superior biotechnological properties, which to characterize traditional products obtained, that are influenced by culture and used as animal feed and soil (Harnann et al., 1997; Trachsel et al., 2000).

In this paper we studied the effect of different culture medium on biomass accumulation of lactic bacteria, bacteria isolated from organic milk from three farms in Sibiu, Romania.

Accumulation of biomass can be distinguished by measuring the optical density of a medium inoculated with lactic bacteria in a predetermined period of fermentation (Iancu et al., 2012; Esbensen et al., 1998; Walstra et al., 1999). Most favorable culture medium will lead to superior biomass accumulation, in the sense that cell multiplication is superior to a less nutritious medium, and the products aroma will be influenced by the use of these bacteria (Timmons et al., 2001; Vanam et al., 1994).

\section{MATERIALS AND METHODS}

\subsection{Isolation of strains Lactobacillus delbrueckii var. bulgaricus}

As a source for the isolation of strains of Lactobacillus delbrueckii var. bulgaricus were used: organic cow's milk coming from the three organic farms denoted by A, B, and C. The milk samples were marked and labeled to identify strains, and decimal dilutions were performed. The last three dilutions were seeded onto solid semiselective medium: MRS medium (peptone $10 \mathrm{~g} / \mathrm{l}$, meat extract $10 \mathrm{~g} / \mathrm{l}$, glucose $20 \mathrm{~g} / \mathrm{l}$, ammonium citrate $2 \mathrm{~g} / \mathrm{l}$, Na-acetate $5 \mathrm{~g} / \mathrm{l}, \mathrm{K}_{2} \mathrm{HPO}_{4} 2 \mathrm{~g} / \mathrm{l}, \mathrm{MgSO}_{4} 0.1 \mathrm{~g} / \mathrm{l}$, $\mathrm{MnSO}_{4} 0.05 \mathrm{~g} / \mathrm{l}$, Tween $801 \mathrm{ml} / \mathrm{l} \mathrm{pH} 6.2$, agar $15 \mathrm{~g} / \mathrm{l}$ ) and medium TS (tryptone $10 \mathrm{~g} / \mathrm{l}$, lactose $10 \mathrm{~g} / \mathrm{l}$, agar $12 \mathrm{~g} / \mathrm{l}$, yeast extract $5 \mathrm{~g} / \mathrm{l}, \mathrm{KH}_{2} \mathrm{PO}_{4} 2 \mathrm{~g} / \mathrm{l}, \mathrm{pH} 6.8$, agar $15 \mathrm{~g} / \mathrm{l}$ ). Purification of the colonies has been performed by taking those colonies with characteristics in terms of color, shape, size, and reseeding on solid MRS. For identification, the strains were subjected to catalase test and Gram staining. Their storage was performed in MRS liquid medium at $-75^{\circ} \mathrm{C}$, in the presence of a cryoprotectant (glycerol 25\%, v/v). In order to test and improve the biotechnological properties, the isolated strains were multiplied on selective culture medium (1g/11) whose composition was enriched with different amounts of sugars, according to the scheme below.

\subsection{Strains of lactic bacteria}

There were selected three strains of bacteria Lactobacillus delbrueckii var. bulgaricus

- Lactobacillus delbrueckii var. bulgaricus - LDBA 24 - isolated from organic milk from Farm A

- Lactobacillus delbrueckii var. bulgaricus - LDBB 16 - isolated from organic milk from Farm B 
- Lactobacillus delbrueckii var. bulgaricus - LDBC 31 - isolated from organic milk from Farm C

\subsection{Culture media (Scharlau chemicals, Barcelona,} EU)

1. MRS culture medium

2. MRS culture medium with addition of $3 \%$ glucose, $2 \%$ lactose and $1 \%$ maltose

3. MRS culture medium with addition of $3 \%$ glucose, $2 \%$ lactose and $1 \%$ raffinose

4. MRS culture medium with addition of $3 \%$ glucose, $2 \%$ lactose and $1 \%$ melibiose

5. MRS culture medium with addition of $1 \%$ glucose, $2 \%$ lactose and $3 \%$ maltose

6. MRS culture medium with addition of $1 \%$ glucose, $2 \%$ lactose and $3 \%$ raffinose

7. MRS culture medium with addition of $1 \%$ glucose, $2 \%$ lactose and $3 \%$ melibiose

8. MRS culture medium with addition of $1 \%$ glucose, $1 \%$ lactose and $1 \%$ maltose
9. MRS culture medium with addition of $1 \%$ glucose, $1 \%$ lactose and $1 \%$ raffinose

10. MRS culture medium with addition of $1 \%$ glucose, $1 \%$ lactose and $1 \%$ melibiose

\subsection{Regime of fermentation}

There were established the following parameters:

- temperature fermentation: $37^{\circ} \mathrm{C}$,

- time: 24 hours

Sartorius fermentor equipped with temperature sensors, $\mathrm{pH}$, optical density $(600 \mathrm{~nm})$, carbon dioxide, oxygen.

\subsection{Statistical analysis}

The results were analyzed using ANOVA statistical program by establishing regression factor.

\section{RESULTS AND DISCUSSION}

Analyzing Figure 1-3 it is observed that the optical density increases both during fermentation and due to the culture medium that was used. In Figure 1-3 it is noted that MRS culture medium with the addition of $1 \%$ glucose, $2 \%$ lactose and $3 \%$ maltose leads to a maximum accumulation of cells over 24 -hour fermentations.

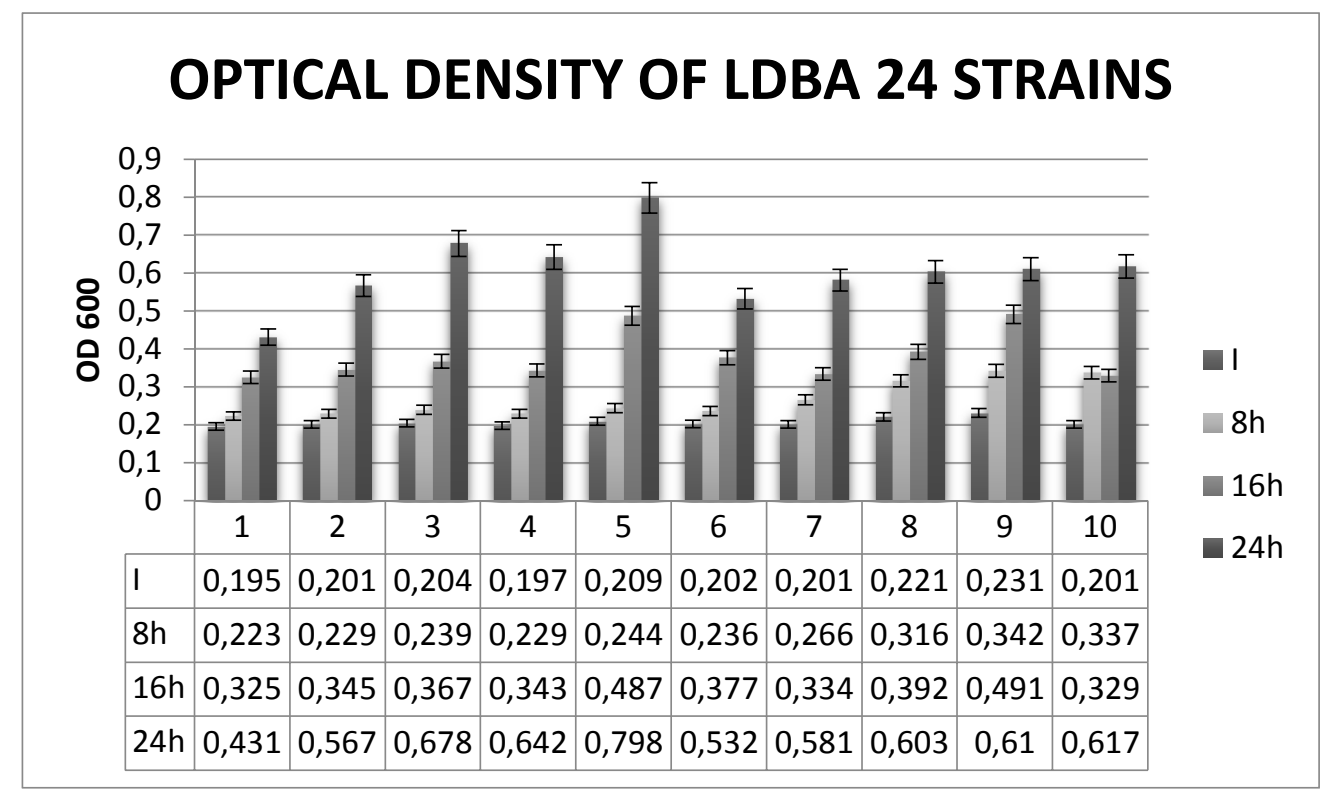

Figure 1. Evolution of the optical density measured at $600 \mathrm{~nm}$ strain Lactobacillus delbrueckii var. Bulgaricus-LDBA 24 - isolated from organic milk from Farm A 


\section{OPTICAL DENSITY OF LDBB 16 \\ STRAINS}

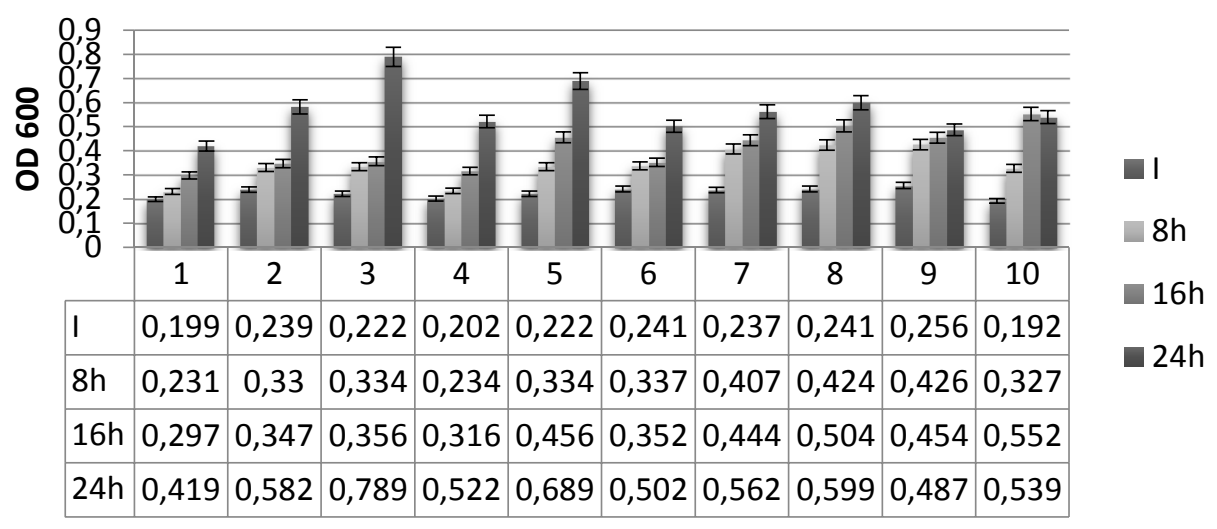

Figure 2. Evolution of the optical density measured at $600 \mathrm{~nm}$ strain Lactobacillus delbrueckii var. Bulgaricus-LDBA 24 - isolated from organic milk from Farm B

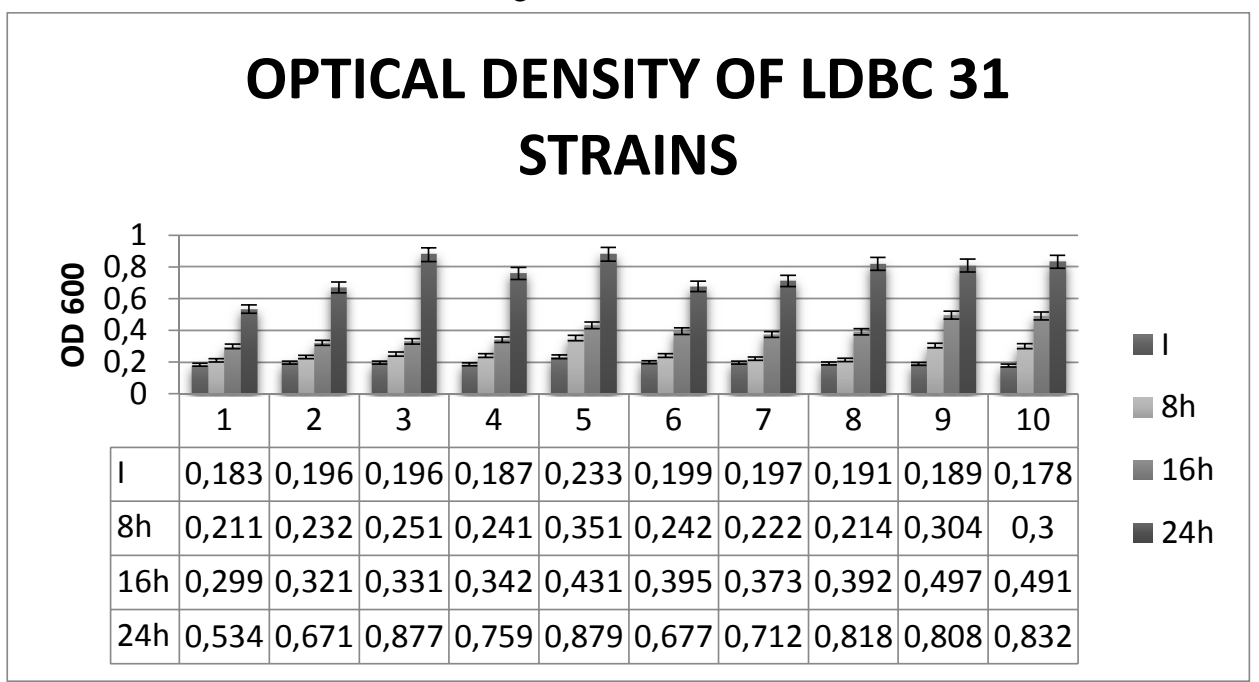

Figure 3. Evolution of the optical density measured at $600 \mathrm{~nm}$ strain Lactobacillus delbrueckii var. Bulgaricus-LDBA 24 - isolated from organic milk from Farm C

Another propitious culture medium for the accumulation of lactic bacteria is culture medium 3 containing an addition of $3 \%$ glucose, $2 \%$ lactose and $1 \%$ raffinose. It is found that the addition of glucose and maltose leads to a more pronounced multiplication of lactic bacteria considered by this study.

Table 1. The results obtained from statistical point of view

SUMMARY OUTPUT

Regression Statistics

\begin{tabular}{|c|c|l|l|l|l|l|}
\hline Multiple R & 0,780669 & & & & & \\
\hline R Square & 0,609443 & & & & & \\
\hline $\begin{array}{c}\text { Adjusted R } \\
\text { Square }\end{array}$ & 0,414165 & & & & & \\
\hline Standard Error & 2,317359 & & & & & \\
\hline Observations & 10 & & & & & \\
\hline
\end{tabular}

ANOVA

\begin{tabular}{|c|c|c|c|c|c|c|}
\hline & $d f$ & $S S$ & $M S$ & $F$ & Significance $F$ & \\
\hline Regression & 3 & 50,27908 & 16,75969 & 3,120897 & 0,10943 & \\
\hline Residual & 6 & 32,22092 & 5,370153 & & & \\
\hline Total & 9 & 82,5 & & & & \\
\hline
\end{tabular}




\begin{tabular}{|c|c|c|c|c|c|c|}
\hline & & & & & & \\
\hline & Coefficients & $\begin{array}{c}\text { Standard } \\
\text { Error }\end{array}$ & $t$ Stat & P-value & Lower 95\% & $\begin{array}{c}\text { Upper } \\
95 \%\end{array}$ \\
\hline Intercept & $-2,32373$ & 5,484457 & $-0,42369$ & 0,686558 & $-15,7437$ & 11,09625 \\
\hline X Variable 1 & $-6,35358$ & 17,76193 & $-0,35771$ & 0,732809 & $-49,8155$ & 37,10831 \\
\hline X Variable 2 & $-29,308$ & 10,93363 & $-2,68054$ & 0,03651 & $-56,0616$ & $-2,55438$ \\
\hline X Variable 3 & 37,80703 & 17,45459 & 2,166023 & 0,073464 & $-4,90281$ & 80,51686 \\
\hline
\end{tabular}

RESIDUAL OUTPUT

\begin{tabular}{|c|c|c|c|c|c|c|}
\hline Observation & Predicted $Y$ & Residuals & & Percentile & $Y$ & \\
\hline 1 & 2,84678 & $-1,84678$ & & 5 & 1 & \\
\hline 2 & 2,385052 & $-0,38505$ & & 15 & 2 & \\
\hline 3 & 3,401297 & $-0,4013$ & & 25 & 3 & \\
\hline 4 & 6,994032 & $-2,99403$ & & 35 & 4 & \\
\hline 5 & 5,645282 & $-0,64528$ & & 45 & 5 & \\
\hline 6 & 5,178909 & 0,821091 & & 55 & 6 & \\
\hline 7 & 4,43235 & 2,56765 & & 65 & 7 & \\
\hline 8 & 7,21572 & 0,78428 & & 75 & 8 & \\
\hline 9 & 10,07567 & $-1,07567$ & & 85 & 9 & \\
\hline 10 & 6,824906 & 3,175094 & & 95 & 10 & \\
\hline
\end{tabular}

Table 2. Regression Statistics

Regression Statistics

\begin{tabular}{|c|c|c|}
\hline Multiple R & 0,780669 & Ry, $x=\sqrt{\frac{\sum_{i=1}^{n}\left(\hat{y}_{i}-\bar{y}\right)^{2}}{\sum_{i=1}^{n}\left(y_{i}-\bar{y}\right)^{2}}}=\sqrt{1-\frac{\sum_{i=1}^{n}\left(y_{i}-\hat{y}_{i}\right)^{2}}{\sum_{i=1}^{n}\left(y_{i}-\bar{y}\right)^{2}}}$ \\
\hline R Square & 0,609443 & $R^{2}=\frac{\Delta_{y / x}^{2}}{\Delta_{y}^{2}}=1-\frac{\Delta_{e}^{2}}{\Delta_{y}^{2}}=\frac{\sum_{i=1}^{n}\left(\hat{y}_{i}-\bar{y}\right)^{2}}{\sum_{i=1}^{n}\left(y_{i}-\bar{y}\right)^{2}}$ \\
\hline Adjusted R Square & 0,414165 & $\overline{\mathrm{R}}^{2}=1-\frac{\Delta_{\mathrm{u}}^{2} / \mathrm{n}-\mathrm{k}-1}{\Delta_{\mathrm{y}}^{2} / \mathrm{n}-1}$ \\
\hline Standard Error & 2,317359 & $\mathrm{~s}_{\mathrm{u}}=\sqrt{\frac{\Delta_{\mathrm{u}}^{2}}{\mathrm{n}-2}}=\sqrt{\frac{\sum_{\mathrm{i}=1}^{\mathrm{n}}\left(\mathrm{y}_{\mathrm{i}}-\hat{\mathrm{y}}_{\mathrm{i}}\right)^{2}}{\mathrm{n}-2}}$ \\
\hline Observations (n) & 10 & \\
\hline
\end{tabular}

ANOVA

\begin{tabular}{|c|c|c|c|c|c|}
\hline $\begin{array}{c}\text { Source } \\
\text { variation }\end{array}$ & $d f$ & $S S$ & $M S=S S / d f$ & $F$ & Significance $F$ \\
\hline Regression & $3(\mathrm{k})$ & $\begin{array}{c}\mathrm{SSR}=\Delta_{\mathrm{x}}^{2}=\sum_{\mathrm{i}=1}^{\mathrm{n}}\left(\hat{\mathrm{y}}_{\mathrm{i}}-\overline{\mathrm{y}}\right)^{2}= \\
50,27908\end{array}$ & $\begin{array}{c}\mathrm{s}_{\mathrm{x}}^{2}=\frac{\Delta_{\mathrm{x}}^{2}}{\mathrm{k}} \\
16,75969\end{array}$ & $\begin{array}{c}\text { Test } \\
\mathrm{F}=3,120897 \\
\mathrm{~F}=s_{x}^{2} / s_{u}^{2}\end{array}$ & $0,10943>0,05$ \\
\hline Residual & $6(\mathrm{n}-\mathrm{k}-1)$ & $\begin{array}{c}\mathrm{SSE}=\Delta_{\mathrm{u}}^{2}=\sum_{\mathrm{i}=1}^{\mathrm{n}}\left(\mathrm{y}_{\mathrm{i}}-\hat{\mathrm{y}}_{\mathrm{i}}\right)^{2}= \\
32,22092\end{array}$ & $\begin{array}{c}\mathrm{s}_{\mathrm{u}}^{2}=\frac{\Delta_{\mathrm{u}}^{2}}{\mathrm{n}-\mathrm{k}-1} \\
5,370153\end{array}$ & & \\
\hline
\end{tabular}




\begin{tabular}{|l|l|c|c|c|c|}
\hline Total & $9(\mathrm{n}-1)$ & $\mathrm{SST}=\Delta_{\mathrm{y}}^{2}=\sum_{\mathrm{i}=1}^{\mathrm{n}}\left(\mathrm{y}_{\mathrm{i}}-\overline{\mathrm{y}}\right)^{2}=$ \\
$\begin{array}{c}82,5 \\
\mathrm{SST}=\mathrm{SSR}+\mathrm{SSE}\end{array}$ & $\mathrm{s}_{\mathrm{y}}^{2}=\frac{\Delta_{\mathrm{y}}^{2}}{\mathrm{n}-1}$ & & \\
\hline
\end{tabular}

\begin{tabular}{|c|c|c|c|c|c|c|}
\hline & Coefficients & $\begin{array}{c}\text { Standard } \\
\text { Error }\end{array}$ & t Stat & P-value & Lower 95\% & Upper 95\% \\
\hline Intercept & $\mathrm{a}_{0}=-2,32373$ & $S_{a_{0}}=5,484457$ & $-0,42369$ & 0,686558 & $-0,82493$ & 1,10932 \\
\hline Temps & $\mathrm{a}_{1}=-6,35358$ & $\mathrm{~S}_{\mathrm{a} 1}=17,76193$ & $-0,35771$ & 0,732809 & 0,131488 & 1,01732 \\
\hline & $\mathrm{a}_{2}=-29,308$ & $\mathrm{~S}_{\mathrm{a} 2}=10,93363$ & $-2,68054$ & 0,03651 & $-0,52261$ & 0,623911 \\
\hline & $\mathrm{a}_{3}=37,80703$ & $\mathrm{~S}_{\mathrm{a} 3}=17,45459$ & 2,166023 & 0,073464 & $-0,60223$ & 0,213042 \\
\hline
\end{tabular}

Interpreting results from Table SUMMARY OUTPUT:

$\mathrm{R}=0.780669$ shows that between the control sample and subsequent samples there is a strong connection.

$\mathrm{R}^{2}=0.609443$ shows that $60.9 \%$ of the variation in the number of blank samples is explained by subsequent tests determined.

Standard deviation of error $=5.484457$. If this indicator is zero means that all points are on the regression line.

In this table is calculated $\mathrm{F}$ test for regression model validation. Since F $=3.120897$ and Significance F (significance) is 0.10943 then built alternative regression model is valid and can be used to analyze the dependence between the two variables. Intercept is the free term, therefore the coefficient $a_{0}$ is -2.32373 . The free term is the point where the explanatory variable (factorial) is 0 . Since $t_{a_{0}}=-0.42369$ and significance threshold $P$-value is $0.686558>0.05$ means that the coefficient is significant in the case of the alternative hypothesis.

$a_{l}$ coefficient is -6.35358 , which means that the probability the biomass increases every time the concentration of sugars in the medium increases. Since $t_{a 1}=-0.35771$ and significance threshold $P$-value is $0.732809>0.05$ means that the coefficient is significant. Confidence interval for this parameter is 0.131488 $\leq \alpha_{1} \leq 1.01732$.

$a_{2}$ coefficient is -29.308 , which means that the amount of biomass increases depending on the type and concentration of sugars in the culture medium. Because $\mathrm{t}_{\mathrm{a} 2}=-2.68054$ and significance threshold $P$-value is $0.03651<0.05$ means that this coefficient is very significant. Confidence interval for this parameter is $-0.52261 \leq \alpha_{1} \leq 0.623911$.

The coefficient $a_{3}$ is 37.80703 , which means that it increases the amount of biomass with $37.80703 \mathrm{~g} / \mathrm{L}$ each time increases the concentration of sugars in the culture medium.

Because $\mathrm{t}_{\mathrm{a} 3}=2.166023$ and $P$-value significance threshold is 0.07> 0.05 means that this coefficient is less significant. Confidence interval for this parameter is $-0.60223 \leq \alpha_{1} \leq$ 0.213042 .

\section{CONCLUSIONS}

Obtaining lactic bacteria biomass depends on the culture medium used, as well as the type of sugars used for enriching them.

Sugars lead to a higher multiplication of lactic bacteria, but this is directly proportional to the chosen type.
The statistical interpretation leads to the selection of optimum multiplication variant and correct prediction results.

Selected regression coefficients lead to standard error calculation that can be decreased and then lies on the regression line or if they are higher is located at distance of the regression line.

Statistical analysis is necessary in order to provide information on what concerns predictive correlation between selected variables, in our case the culture medium composition and biomass accumulation of lactic bacteria Lactobacillus delbrueckii var. bulgaricus.

Isolation of lactic bacteria from organic milk lead to obtaining of products with ecological characteristics and natural.

\section{REFERENCES}

1. ESBENSEN, K., SCHÖNKOPF, S., MITDGAARD, T. \& GUYOT, D. (1998): Multivariate analysis in practice. A training package. Oslo: CAMO ASA development and support.

2. HAMANN, J. \& KRÖMKER, V. (1997): Potential of specific milk composition variables for cow health management. Livestock Production Science, 48, 201-208.

3. IANCU, R. (2011): The Influence of Extensive System on Goat Milk, Scientific Papers: Animal Science and Biotechnologies, 44 (2), 417-420.

4. IANCU, R., OPREAN, L., TITA, M., LENGYEL, E. \& CODOI, V. (2012): Microbiological Appraisal of Goat Milk under Traditional Management Practices, Proceeding of the International Conference "Agricultural and Food Science, Processes and Technologies" AGRIFOOD 20, Sibiu, Romania, ISSN 1843-0694, 352-357.

5. TRACHSEL, P., BUSATO, A. \& BLUM, J.W. (2000): Body conditions scores of dairy cattle in organic farms. Journal of Animal Physiology and Animal Nutrition, 84, $112-124$.

6. TIMMONS, J.S, WEISS, P., PALMQUIST, D.L. \& HARPERT, W.J. (2001): Relationships among dietary roasted soybeans, milk components, and spontaneous oxidized flavor of milk, J. Dairy Sci. 84, 2440-2449

7. TIŢA, M.A. (2002): Manual de analiza şi controlul calitaţii in industria laptelui, Ed. Universitatii Lucian Blaga, Sibiu.

8. TIŢA, M.A., OTTO, K., IANCU, R. \& MUHAMMAD, R. (2011): Evaluation of microbiological and physicochemical quality of raw milk from Sibiu dairy farm province of Romania, Animal Science and Biotechnologies Bulletin of University of Agricultural Sciences and Veterinary Medicine Cluj-Napoca, 68 (2), 463-468. 
9. VARNAM, A.H. \& SUTHERLAND, J.P. (1994): Milk and Milk Products - Technology, chemistry and microbiology. London: Chapman \& Hall.
10. WALSTRA, P., GEURTS, T.J., NOOMEN, A., JELLEMA, A. \& BOEKEL, M. (1999): Dairy Technology - principles of milk properties and processes. New York: Marcel Dekker,Inc. 